\title{
COMUNICAÇÃO
}

\section{AVALIAÇÃO DA COLORAÇÃO DE BASIDIOCARPOS DESIDRATADOS DE Agaricus blazei SEGUNDO ESCALA DE MUNSELL ${ }^{1}$}

\author{
Evaluation of the dehydrated fruiting bodies of the mushroom Agaricus blazei \\ according to munsell colour scale
}

\author{
Marisa Aparecida da Fonseca Delú , Eustáquio Souza Dias ${ }^{3}$, Rosane Freitas Schwan ${ }^{3}$, \\ Eduardo Valério de Barros Vilas Boas ${ }^{4}$
}

\begin{abstract}
RESUMO
Com este trabalho objetivou-se avaliar a coloração final de basidiocarpos desidratados de Agaricus blazei, após serem submetidos a tratamento com ácidos ascórbico e cítrico. Para tanto, utilizaram-se cogumelos A. blazei, cultivados em substrato apropriado e mantidos em estufa. Os cogumelos foram colhidos com o píleo totalmente fechado e após a limpeza em água corrente, os basidiocarpos foram seccionados ao meio no sentido longitudinal, sendo uma metade submetida ao tratamento experimental e a outra metade representando o tratamento controle. Os tratamentos experimentais consistiram da imersão das metades dos basidiocarpos em solução de ácido ascórbico comercial nas concentrações de 0,10, 20 e $30 \mathrm{mg} / \mathrm{L}$ durante 0, 2, 5, 10,15 ou 20 minutos. Para o ácido cítrico foram testadas as mesmas concentrações anteriores, porém nos tempos de imersão de 0,10 e 15 minutos. Todos os tratamentos consistiram de 3 repetições cada. Não se observou relação entre os tratamentos utilizados com a coloração final dos basidiocarpos, embora a utilização de substâncias ácidas tenha possibilitado a obtenção de basidiocarpos desidratados mais próximos daquela coloração considerada ideal para comercialização.
\end{abstract}

Termos para indexação: Cogumelos, padronização da coloração, pós-colheita.

\begin{abstract}
The main aim of this work was to evaluate the final colour of the fructification bodies of the mushroom Agaricus blazei submitted to ascorbic and citric acid treatment. The mushroom Agaricus blazei was cultivated in an appropriated substrate and storage in incubators. The mushroom was harvested containing closed pileus and after cleaning with running tap water, the fruiting bodies were sliced and half of each were submitted to acid treatment and half was the control (water immersion). The experimental treatment consisted of immersing half of each basiodiocarp in different concentrations of the commercial solution of ascorbic acid $(0$, 10,20 and $30 \mathrm{mg} / \mathrm{ml}$ during $0,2,5,10,15$ and 20 minutes). The other parts of fruiting bodies were also tested in the same concentrations of citric acid for 0,10 and 15 minutes. All the treatments were done in 3 replicates. According to the Munsell colour scale it was not observed difference in the colour of the basidiocarps among the treatments used in this work.
\end{abstract}

Index terms: Mushroom, colour scale, postharvest.

(Recebido para publicação em 28 de abril de 2004 e aprovado em 11 julho de 2005)

Os cogumelos, bastante utilizados como uma iguaria na culinária, estão sendo atualmente reconhecidos também por suas propriedades medicinais. O cogumelo Agaricus blazei, de origem brasileira, vem sendo utilizado para fins medicinais, sobretudo em países asiáticos. No Brasil, seu cultivo começa a ser intensificado, principalmente visando o mercado externo, apesar do mercado brasileiro estar se mostrando bastante promissor, principalmente depois que lhe foram atribuídas propriedades antitumorais (ITO et al., 1997; OSAKI et al., 1994).

Uma produção comercialmente satisfatória desse basidiocarpo deve ser caracterizada pelo peso, tamanho e coloração adequados. Eira (2003) descreveu quatro grupos que os cogumelos desidratados podem ser classificados, sendo que os grupos adequados para exportação e uma comercialização satisfatória seriam os tipos A+e A, medindo de 7 a $8 \mathrm{~cm}$ e 5 a $7 \mathrm{~cm}$, respectivamente, sem apresentar manchas ou defeitos adicionais (quebrados, muito escuros, talos finos e compridos) e com uma coloração amarelo dourada. Os cogumelos do tipo B e C seriam destinados ao mercado interno e à fabricação de cápsulas, pois apresentam formatos irregulares, tamanhos menores e coloração escura ou muito esbranquiçada. No entanto a falta de tecnologia pós-colheita, devido ao escurecimento enzimático, causado pela ação indesejada da enzima polifenoloxidase (PFO), que atua tanto em vegetais quanto em fungos, prejudica a comercialização do produto reduzindo seu preço e muitas vezes tornando o produto inaceitável pelo consumidor.

\footnotetext{
1 Parte da dissertação do primeiro autor para obtenção do título de Mestre em Microbiologia Agrícola - DBI/UFLA.

2 Estudante de Doutorado em Ciência dos Alimentos/UFLA - Cx. P. 3037 - 37200-000 - Lavras, MG - marisa@ufla.br

${ }^{3}$ Professores do DBI - Universidade Federal de Lavras/UFLA - Cx. P. 3037 - 37200-000 - Lavras, MG.

${ }^{4}$ Professor do DCA - Universidade Federal de Lavras/UFLA - Cx. P. 3037 - 37200-000 - Lavras, MG.
} 
Diversos trabalhos procuram identificar possíveis substâncias que quando utilizadas aumentariam a vida de prateleira de cogumelos frescos (BRENNAN et al., 1999; KUYPER et al., 1993) embora até o momento nenhum trabalho tenha sido localizado que enfoque tratamentos efetivos para melhor conservação e ou padronização da cor do A. blazei, uma vez que ele é comercializado desidratado.

A cor é um fator importante para valorizar a qualidade de um alimento, todavia essa avaliação visual é sempre controversa, uma vez que sempre haverá a interferência do fator humano, gerando um conceito em que a subjetividade pode ser comprovadamente impossível de ser eliminada por completo (PEDROSA, 1995).

Nesse sentido, procurando obter a coloração ideal para seus cogumelos, produtores rurais, ainda que de forma empírica, têm utilizado algumas substâncias, sendo o ácido ascórbico comercial a mais comumente empregada na tentativa de se evitar o escurecimento excessivo nos basidiocarpos desidratados.

Neste trabalho foram avaliados possíveis efeitos do ácido cítrico e ácido ascórbico, em diferentes concentrações, na coloração final dos basidiocarpos de $A$. blazei, utilizando como referência para a avaliação do resultado final, a escala de cores segundo Munsell (1976).

Os cogumelos utilizados neste trabalho pertencem a linhagem CS1 de A. blazei da coleção do Laboratório de Fungos Comestíveis, do Setor de Microbiologia no Departamento de Biologia da UFLA, Lavras, MG. Para o cultivo dos cogumelos utilizou-se um composto previamente colonizado com amostras de micélios do A. blazei e transferido para uma estufa, onde recebeu $5 \mathrm{~cm}$ de cobertura de terra de barranco arenoargilosa, mantida à umidade de $70 \%$ e temperatura entre 20 e $28^{\circ} \mathrm{C}$, durante todo o período de produção. Os basidiocarpos foram colhidos antes que houvesse a abertura do píleo e antes que se iniciasse a ruptura do véu que protege as lamelas, cerca de vinte dias após o início da incubação do composto. Após a colheita e lavagem dos basidiocarpos, estes foram seccionados no sentido longitudinal ao meio e imediatamente submetidos aos diferentes tratamentos, observando que, as duas metades obtidas de cada basidiocarpo foram submetidas, uma, ao tratamento experimental, e a outra utilizada como controle (imersão somente em água) para que o estado morfofisiológico dos cogumelos não interferisse na leitura dos resultados.

As substâncias foram testadas em esquema fatorial com 3 repetições para cada tratamento. Inicialmente utilizou-se o ácido ascórbico comercial nas concentrações de $0,10,15$ e $20 \mathrm{mg}$ por litro de água, nos tempos de imersão de $0,2,5,10,15$ e 20 minutos. Em um segundo experimento testou-se o ácido cítrico em concentrações de 0, 10, 20 e 30 mg por litro nos tempos de imersão de 0,10 e 15 minutos, respectivamente. Após a imersão nos diferentes tratamentos, as metades dos basidiocarpos foram transferidas para uma estufa à temperatura constante de $50^{\circ} \mathrm{C}$ com circulação de ar forçada, por 24 horas. As amostras desidratadas foram embaladas por lotes, segundo o tratamento a que foram submetidas e acondicionadas a $4^{\circ} \mathrm{C}$ para posterior avaliação da coloração final do produto.

As amostras dos experimentos com ácidos cítrico e ascórbico foram submetidas à avaliação de cor com base nos índices de coloração segundo o catálogo de cores de Munsell (1976). Devido à subjetividade imprimida pelas cores, as amostras foram analisadas por duas pessoas, em diferentes momentos e sem que tivessem acesso aos resultados observados pela outra pessoa. Na tentativa de se aproximar ao máximo os dados colhidos, as amostras que apresentaram divergências quanto aos resultados, foram novamente submetidas à análise pelos avaliadores em conjunto até que se chegassem a um consenso. Os basidiocarpos de todas as amostras foram fotografados antes de cada análise, obtendo assim um registro visual nas diversas fases de amostragem no decorrer do experimento.

Primeiramente, fez-se a qualificação da coloração dos basidiocarpos tratados com ácido ascórbico (Tabela 1) e ácido cítrico (Tabela 2) nas diferentes concentrações e tempos de imersão. Notadamente, todos os basidiocarpos desidratados apresentaram um escurecimento em relação ao momento da sua colheita, alterando sua coloração de branco para tons amarelados ou amarronzados. Nesse caso, o escurecimento observado parece fazer parte do próprio processo de desidratação do basidiocarpo (MAU et al., 1993).

Para a avaliação da cor, foram consideradas duas diferentes regiões dos basidiocarpos: as bordas e a região interna. Essa divisão foi necessária por haver significativa diferença na coloração entre as duas regiões, tornando-se impossível classifica-las em uma só cor.

Conclui-se, portanto, que os diferentes tratamentos não produziram nenhum efeito que padronizasse a coloração dos basidiocarpos. A utilização do catálogo de Munsell continua a contar com o fator da subjetividade, embora numa escala já muito mais reduzida, o que certamente reduz possíveis interferências tendenciosas no sentido de valorizar ou desvalorizar o produto no momento da sua comercialização. 
TABELA 1 - Efeito do tempo de imersão e das diferentes concentrações de ácido ascórbico na coloração final de basidiocarpos Agaricus blazei, com base no catálogo de cores segundo Munsell (1976).

\begin{tabular}{|c|c|c|c|c|c|c|}
\hline \multirow[t]{4}{*}{ Tratamento } & \multicolumn{6}{|c|}{ Tempo de Imersão } \\
\hline & & & \multicolumn{2}{|c|}{2 minutos } & & \\
\hline & \multicolumn{2}{|c|}{ Região Interna } & & & \multicolumn{2}{|c|}{ Moído } \\
\hline & Página & Croma & Página & Croma & Página & Croma \\
\hline$\underline{\text { Controle }}$ & $\underline{2,5 \mathrm{Y}}$ & $\underline{8 / 10}$ & $\underline{2,5 \mathrm{Y}}$ & $\underline{8 / 10}$ & $\underline{2,5 \mathrm{Y}}$ & $\underline{8,5 / 10}$ \\
\hline $10 \mathrm{ppm}$ & $2,5 \mathrm{Y}$ & $8,5 / 6$ & $2,5 \mathrm{Y}$ & $8 / 12$ & $2,5 \mathrm{Y}$ & $7 / 8$ \\
\hline $20 \mathrm{ppm}$ & $2,5 \mathrm{Y}$ & $8 / 10$ & $2,5 \mathrm{Y}$ & $8 / 10$ & $2,5 \mathrm{Y}$ & $8 / 12$ \\
\hline \multirow[t]{4}{*}{$30 \mathrm{ppm}$} & $2,5 \mathrm{Y}$ & $8,5 / 6$ & $2,5 \mathrm{Y}$ & $8,5 / 8$ & $2,5 \mathrm{Y}$ & $8 / 10$ \\
\hline & \multicolumn{6}{|c|}{5 minutos } \\
\hline & \multicolumn{2}{|c|}{ Região Interna } & \multicolumn{2}{|c|}{ Bordas } & \multicolumn{2}{|c|}{ Moído } \\
\hline & Página & Croma & Página & Croma & Página & Croma \\
\hline$\underline{\text { Controle }}$ & $\underline{5 \mathrm{Y}}$ & $\underline{8,5 / 6}$ & $\underline{2,5 \mathrm{Y}}$ & $\underline{8,5 / 6}$ & $\underline{2,5 \mathrm{Y}}$ & $\underline{8,5 / 6}$ \\
\hline $10 \mathrm{ppm}$ & $2,5 \mathrm{Y}$ & $8,5 / 6$ & $2,5 \mathrm{Y}$ & $8 / 10$ & $2,5 \mathrm{Y}$ & $8 / 8$ \\
\hline $20 \mathrm{ppm}$ & $2,5 \mathrm{Y}$ & $8,5 / 6$ & $2,5 \mathrm{Y}$ & $8 / 10$ & $2,5 \mathrm{Y}$ & $8 / 10$ \\
\hline \multirow[t]{4}{*}{$30 \mathrm{ppm}$} & $5 \mathrm{Y}$ & $9 / 6$ & $2,5 \mathrm{Y}$ & $8 / 10$ & $2,5 \mathrm{Y}$ & $8 / 10$ \\
\hline & \multicolumn{6}{|c|}{10 minutos } \\
\hline & \multicolumn{2}{|c|}{ Região Interna } & \multicolumn{2}{|c|}{ Bordas } & \multicolumn{2}{|c|}{ Moído } \\
\hline & Página & Croma & Página & Croma & Página & Croma \\
\hline Controle & $\underline{5 \mathrm{Y}}$ & $\underline{9 / 2}$ & $\underline{5 \mathrm{Y}}$ & $\underline{9 / 2}$ & $\underline{2,5 \mathrm{Y}}$ & $\underline{9 / 2}$ \\
\hline $10 \mathrm{ppm}$ & $2,5 \mathrm{Y}$ & $8,5 / 6$ & $2,5 \mathrm{Y}$ & $8,5 / 8$ & $2,5 \mathrm{Y}$ & $9 / 6$ \\
\hline $20 \mathrm{ppm}$ & $5 \mathrm{Y}$ & $8,5 / 8$ & $2,5 \mathrm{Y}$ & $8 / 10$ & $2,5 \mathrm{Y}$ & $8 / 10$ \\
\hline \multirow[t]{4}{*}{$30 \mathrm{ppm}$} & $2,5 \mathrm{Y}$ & $8,5 / 6$ & $2,5 \mathrm{Y}$ & $8 / 12$ & $2,5 \mathrm{Y}$ & $8 / 12$ \\
\hline & \multicolumn{6}{|c|}{15 minutos } \\
\hline & \multicolumn{2}{|c|}{ Região Interna } & \multicolumn{2}{|c|}{ Bordas } & \multicolumn{2}{|c|}{ Moído } \\
\hline & Página & Croma & Página & Croma & Página & Croma \\
\hline Controle & $\underline{5 \mathrm{Y}}$ & $\underline{9 / 4}$ & $\underline{5 \mathrm{Y}}$ & $9 / 4$ & $\underline{2,5 \mathrm{Y}}$ & $\underline{9 / 4}$ \\
\hline $10 \mathrm{ppm}$ & $2,5 \mathrm{Y}$ & $8,5 / 8$ & $2,5 \mathrm{Y}$ & $7 / 12$ & $2,5 \mathrm{Y}$ & $9 / 4$ \\
\hline $20 \mathrm{ppm}$ & $2,5 \mathrm{Y}$ & $8 / 10$ & $2,5 \mathrm{Y}$ & $7 / 10$ & $5 \mathrm{Y}$ & $9 / 6$ \\
\hline \multirow[t]{4}{*}{$30 \mathrm{ppm}$} & $2,5 \mathrm{Y}$ & $8 / 10$ & $2,5 \mathrm{Y}$ & $8 / 12$ & $2,5 \mathrm{Y}$ & $7 / 10$ \\
\hline & \multicolumn{6}{|c|}{20 minutos } \\
\hline & \multicolumn{2}{|c|}{ Região Interna } & \multicolumn{2}{|c|}{ Bordas } & \multicolumn{2}{|c|}{ Moído } \\
\hline & Página & Croma & Página & Croma & Página & Croma \\
\hline$\underline{\text { Controle }}$ & $\underline{2,5 \mathrm{Y}}$ & $\underline{8,5 / 10}$ & $\underline{2,5 \mathrm{Y}}$ & $\underline{8,5 / 10}$ & $\underline{2,5 \mathrm{Y}}$ & \\
\hline $10 \mathrm{ppm}$ & $2,5 \mathrm{Y}$ & $8,5 / 10$ & $2,5 \mathrm{Y}$ & $7 / 12$ & $2,5 \mathrm{Y}$ & $8 / 8$ \\
\hline $20 \mathrm{ppm}$ & $2,5 \mathrm{Y}$ & $8 / 10$ & $2,5 \mathrm{Y}$ & $8 / 12$ & $2,5 \mathrm{Y}$ & $8 / 6$ \\
\hline $30 \mathrm{ppm}$ & $2,5 \mathrm{Y}$ & $8,5 / 6$ & $2,5 \mathrm{Y}$ & $8,5 / 12$ & $2,5 \mathrm{Y}$ & $8 / 12$ \\
\hline
\end{tabular}

* Negrito: Cogumelos mais escuros. 
TABELA 2 - Efeito do tempo de imersão e das diferentes concentrações de ácido cítrico na coloração final de basidiocarpos Agaricus blazei, com base na tabela de cores segundo Munsell (1976).

\begin{tabular}{|c|c|c|c|c|c|c|}
\hline \multirow[t]{4}{*}{ Tratamento } & \multicolumn{6}{|c|}{$\begin{array}{l}\text { Tempo de Imersão } \\
\text { (ácido cítrico) }\end{array}$} \\
\hline & \multicolumn{6}{|c|}{10 minutos } \\
\hline & \multicolumn{2}{|c|}{ Região Interna } & \multicolumn{2}{|c|}{ Bordas } & \multicolumn{2}{|c|}{ Moído } \\
\hline & Página & Croma & Página & Croma & Página & Croma \\
\hline Controle & $5 \mathrm{Y}$ & $9 / 2$ & $5 \mathrm{Y}$ & $9 / 2$ & $2,5 \mathrm{Y}$ & $9 / 2$ \\
\hline $10 \mathrm{ppm}$ & $2,5 \mathrm{Y}$ & $7 / 10$ & $2,5 \mathrm{Y}$ & $7 / 8$ & $2,5 \mathrm{Y}$ & $7 / 12$ \\
\hline $20 \mathrm{ppm}$ & $5 \mathrm{Y}$ & $9 / 6$ & $2,5 \mathrm{Y}$ & $7 / 8$ & $2,5 \mathrm{Y}$ & $7 / 12$ \\
\hline \multirow[t]{4}{*}{$30 \mathrm{ppm}$} & $2,5 \mathrm{Y}$ & $8 / 10$ & $2,5 \mathrm{Y}$ & $7 / 8$ & $2,5 \mathrm{Y}$ & $7 / 12$ \\
\hline & \multicolumn{6}{|c|}{15 minutos } \\
\hline & \multicolumn{2}{|c|}{ Região Interna } & \multicolumn{2}{|c|}{ Bordas } & \multicolumn{2}{|c|}{ Moído } \\
\hline & Página & Croma & Página & Croma & Página & Croma \\
\hline Controle & $5 \mathrm{Y}$ & $9 / 4$ & $5 Y$ & $9 / 4$ & $2,5 \mathrm{Y}$ & $9 / 4$ \\
\hline $10 \mathrm{ppm}$ & $2,5 \mathrm{Y}$ & $8,5 / 10$ & $2,5 \mathrm{Y}$ & $7 / 10$ & $2,5 \mathrm{Y}$ & $8 / 12$ \\
\hline $20 \mathrm{ppm}$ & $2,5 \mathrm{Y}$ & $8,5 / 10$ & $2,5 \mathrm{Y}$ & $7 / 10$ & $2,5 \mathrm{Y}$ & $8 / 12$ \\
\hline $30 \mathrm{ppm}$ & $2,5 \mathrm{Y}$ & $8,5 / 10$ & $2,5 \mathrm{Y}$ & $7 / 10$ & $2,5 \mathrm{Y}$ & $8 / 12$ \\
\hline
\end{tabular}

* Negrito: Cogumelos mais escuros.

\section{REFERÊNCIAS BIBLIOGRÁFICAS}

BRENNAN, M.; PORT, G. L.; PULVERENTI, A.; GORMLEY, $\mathrm{R}$. The effect of sodium metabisulfite on the whiteness and keeping quality of sliced mushrooms. LebensmittelWissensccchaft und Techonologie, London, v. 32, n. 7, p. 460-463, 1999.

EIRA, A. F. da. Cultivo do cogumelo medicinal Agaricus blazei. Viçosa: Aprenda Fácil, 2003. 398 p.

ITO, H.; SHIMURA, K.; ITOH, H.; KAWADE, M. Antitumor effects of a new polyssaccharide-protein complex (ATOM) prepared from Agaricus blazei (Iwade strain 101) "himematsutake" and its mechanism in tumor-bearing mice. Anticancer Research, Athens, v. 17, n. 1A, p. 277-284, Jan./Feb. 1997.

KUYPER, L.; WELNERT, I. A. C.; McGILL, A. E. J. The effect of modified atmosphere packaging and addition of calcium hypochloride on the atmosphere composition, colour and microbial quality of mushrooms. LebensmittelWissenschaft uund Techonology, London, v. 26, n. 1, p. 14-20, 1993.

MAU, J. L.; MIKLUS, M. B.; BEELMAN, R. B. Shelf life of Agaricus mushrooms. In: CHARALAMBOUS, G. Shelf life of foods and beverages. [S.1.: s.n.], 1993. p. 255-293.

MUNSELL, A. H. Munsell book of color. Baltimore: Macbeth Division of Kollmorgen, 1976. (Mathefinish collection).

PEDROSA, I. Da cor à cor inexistente. Rio de Janeiro: L . Christiano, 1995.219 p.

OSAKI, Y.; KATO, T.; YAMAMOTO, K.; OKUBO, J.; MIYAZAKI, T. Antimutagenic and bactericidal substances in the fruit body of a Basidiomycete Agaricus blazei, Jun-17. Yakugaku Zasshi, Tokyo, v. 114, n. 5, p. 342-350, May 1994. 